\title{
Rehabilitating Eutrophic Lakes Using Tree Planting along the Shoreline
}

\author{
Takashi YOSHITAKE*, Kazunori SHIMADA and Michiaki OKANO \\ Department of Meteorological Environment, Forestry and Forest Products Research Institute \\ (Tsukuba, Ibaraki 305-8687, Japan)
}

\begin{abstract}
In order to improve the water quality and shoreline aesthetics of eutrophic lakes in urban areas, we developed a technique for planting trees in the shallow waters along the shore. Our studies indicated that Taxodium seedlings directly planted in water less than $1 \mathrm{~m}$ deep and Salix spp. cuttings planted in perennial water in wetlands, grew well and could become revegetation agents. Floating planters of Taxodium and Salix spp. also grew well. The storage capacity of a $1 \mathrm{~m}$ high Salix gilgiana tree was $13.4 \mathrm{mg}$ for $\mathrm{N}$ and $1.72 \mathrm{mg}$ for $\mathrm{P}$ per day in the growing season. Total absorption of $\mathrm{Zn}$ by the tree form of $T$. distichum 3 months after planting was $9.3 \mathrm{mg} / 100 \mathrm{gdw}$ (dry weight) and that of $\mathrm{Cu}$ was 2.3 $\mathrm{mg} / 100 \mathrm{gdw}$. Moreover, the floating planters attracted fish and waterfowl.
\end{abstract}

Discipline: Forestry and forest products

Additional key words: lakeside forest, Taxodium, Salix, floating planter

\section{Introduction}

Presently there is a growing concern about the gradual loss of the natural environment. Especially, it is important to formulate a strategy for preventing the degradation of life water systems. The eutrophication of rivers, lakes and ponds in urban areas in Japan by Microcystis aeruginosa may adversely affect aquatic organisms and the quality of drinking water. Improvement of the water quality of eutrophic lakes is essential for human and aquatic organisms. We have been examining the water purification ability of woody plants that require several decades of growth until cutting, compared with purification by herbaceous plants such as reeds (Phragmites communis) and waterhyacinths (Eichhornia crassipes). In the present paper, the results of tests for the planting of woody plants for water improvement and revegetation of the shoreline of an eutrophic lake are reported. This study was carried out as a part of the BioRenaissance Program implemented by the Bureau of the Research Council.

\section{Materials and methods}

1) Plants, birds and fish

We selected Salix gilgiana, S. triandra, and Taxo- dium distichum as tree species which could be utilized for the artificial establishment of a lakeside forest. In addition, the herbs Iris pseudacorus and Oenanthe javanica were planted under the trees.

Observations were made to identify the species of wild birds which built nests on the branches of the trees or basal stem, and the species of fish which gathered under the floating planters and rafts on the water surface.

\section{2) Floating planter and raft}

Wooden floating planters with a plastic basket (Fig. 1) and rafts were constructed in order to plant the trees on the water surface. The wooden floating planters for planting S. gilgiana, T. distichum, Iris and Oenanthe javanica were filled with charcoal and pumice.

\section{3) Experimental plot and planting method}

The tests for the planting of $T$. distichum and $S$. gilgiana were carried out in a pond at the Forest and Forest Products Research Institute (FFPRI) and in Kasumigaura Lake. Branches of S. triandra were cut in a reed community which was located in a flood-plain area of Kasumigaura Lake.

T. distichum, S. gilgiana, Iris pseudacorus and Oenanthe javanica were planted in identical planters. $S$. gilgiana was planted in a floating planter for water clarity measurements in the FFPRI pond. The clarity of the 


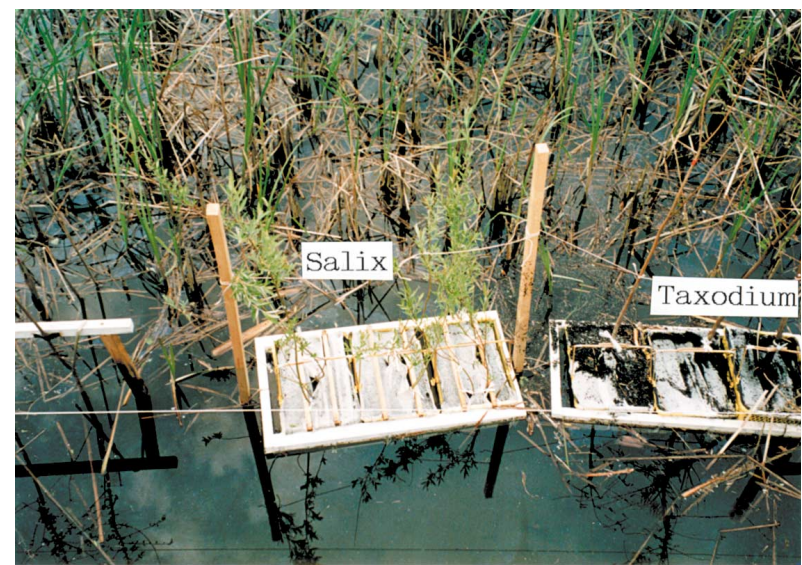

Fig. 1. Floating planter

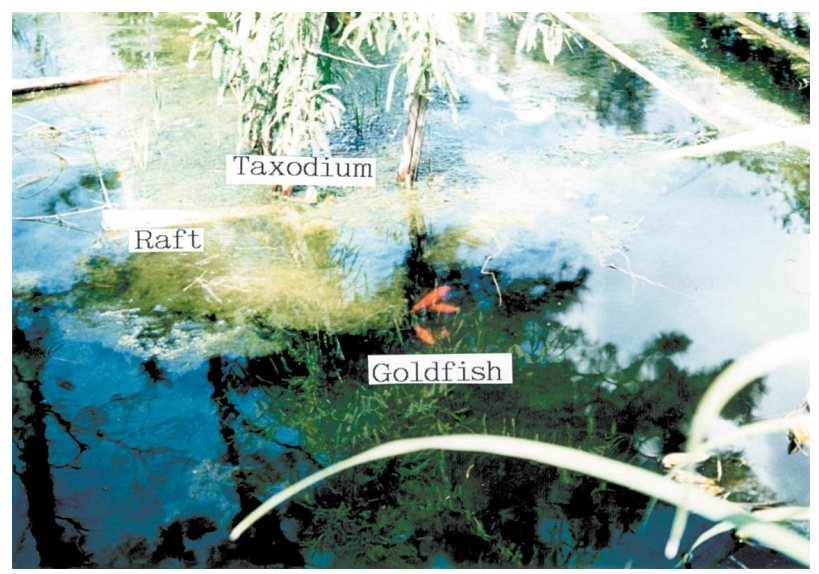

Fig. 3. Goldfish under a raft

water in the planting area was measured using a transparency meter (ST-100, IUCHI Co., Ltd.)

To establish forests between the shoreline and lake bed, an experiment on the direct planting of $T$. distichum into water was conducted in Kasumigaura Lake. T. distichum trees, 150-170 cm, high were planted in water at a depth of $50-80 \mathrm{~cm}$ by binding seedlings to logs or vinyl chloride pipes anchored to the lake bed. The planter (no. 1 test model) consisted of wooden frames with inlaid plastic baskets filled with charcoal as shown in Fig. 1.

The growth of the trees in water was monitored by Yoshitake ${ }^{2)}$, who planted seedlings of $T$. distichum and $S$. gilgiana on a fixed bed on water. To enhance the growth of the trees in aquatic environments, planting experiments were conducted using $T$. distichum and S. gilgiana on floating planters. For the measurement of the absorption function of N and P by S. gilgiana, a tank with a volume of $60 \mathrm{~L}$ containing a solution culture medium $(\mathrm{N}: 15$ mg/L, P:6 mg/L, K:6 mg/L) was used.
4) Analysis of nitrogen, phosphorus, zinc and copper contents of trees

The contents of $\mathrm{N}$ and $\mathrm{P}$ of Salix gilgiana saplings in hydroponic culture were analyzed over a period of 54 days from the onset to the end of the test. The $\mathrm{N}$ content of the trees was analyzed using a fully automatic measurement equipment (TN-301P), and that of $\mathrm{P}$ was analyzed by the industrial liquid waste test method (JIS K0102).

To determine the absorption capacity of $T$. distichum, the contents of $\mathrm{Zn}$ and $\mathrm{Cu}$ were determined before the species were planted in Kasumigaura Lake, and 3 months after planting. The contents of $\mathrm{Zn}$ and $\mathrm{Cu}$ were analyzed by automatic absorption spectrophotometry.

\section{Results}

\section{1) Growth of planted test trees}

Roots of planted T. distichum elongated into the mud at the bottom, and adventitious roots also elongated from stems in water and grew vigorously.

Trees of $T$. distichum planted directly in the reed field in the observation areas grew well after the elongation of newly developed roots into water or mud at the bottom. Two years later, the tree height reached $2 \mathrm{~m}$, as in the case of reeds. On the other hand, seedlings planted in areas that were directly exposed to waves in front of the reed fields stopped growing, because their roots were always being shaken and could not reach the bottom of the lake due to washing of the mud moved by waves at the bottom under the roots.

Planting of $S$. triandra in water was performed to put branches 50-70 $\mathrm{cm}$ long between the stocks of reed. $S$. triandra planted between reeds and directly exposed to waves became covered with many foreign materials (suspended sediment and sphagnum moss) on the surface of the shoots under water, and poor growth was recorded, even when rooting and new development of leaves occurred. On the other hand, twigs planted between small reeds with minimal influence of wave motion along the shoreline showed a good growth in terms of both rooting and development of new leaves.

When T. distichum was planted on the floating planters, both the trees and Iris pseudacorus grew well when algae containing seeds of Iris were used. In addition, $S$. gilgiana and Oenanthe javanica in mixed planting grew well with intertwining of the fine roots of both species. Roots of both species developed inside of the planters were completely interwoven with one another and they appeared like one root system. 


\section{2) Absorption function of N, P, Zn and Cu of trees}

When $S$. gilgiana (average height $98.5 \mathrm{~cm}$, average total dry weight $166 \mathrm{~g}$ ) grew in a culture solution containing $15 \mathrm{mg} / \mathrm{L}$ of $\mathrm{N}, 6 \mathrm{mg} / \mathrm{L}$ of $\mathrm{P}$ and $6 \mathrm{mg} / \mathrm{L}$ of $\mathrm{K}$ (potassium) for 54 days, the trees stored $436 \mathrm{mg}$ of $\mathrm{N}$ and 0.56 $\mathrm{mg}$ of $\mathrm{P}$ per $\mathrm{g}$ for $\mathrm{dw}$ (dry weight). The storage capacity of a $1 \mathrm{~m}$ high S. gilgiana tree was $13.4 \mathrm{mg}$ for $\mathrm{N}$ and 1.72 mg for P per day ${ }^{1)}$.

The total absorption of $\mathrm{Zn}$ by the tree form of $T$. distichum at 3 months after planting was $9.3 \mathrm{mg} / 100 \mathrm{gdw}$, and that of $\mathrm{Cu}$ was $2.3 \mathrm{mg} / 100 \mathrm{gdw}$.

\section{3) Clarity of the water}

The water in the floating planter on which S. gilgiana had been planted was 1.8 times clearer than the water in the pond in the control (Fig. 2).

\section{4) Attraction of fish and birds to forest}

Several species of pond fish (carp, goldfish, crucian carp, Pseudorasbora parva, threading goby) gathered under the rafts and floating planters just after the beginning of the experiment. Results of our observations indicated that the fish gathered in these areas to catch food and to lay eggs. In the first 10-day period of June, when egg laying started, fish gathered under the rafts and floating planters for feeding on eggs as shown in Fig. $3^{2,33}$.

Numerous algae on the surface of the roots of $S$. gilgiana and T. distichum planted on the floating planters became habitats for aquatic organisms, such as hydra, water flea, rotatoria and paramecium during the growth. We often observed that heads of Pseudorasbora parva and Carassius gibelio penetrated into the roots of the planted trees, presumably for feeding on the plankton grown among the roots. In addition, fish often took refuge under floating planters presumably to avoid their enemies $^{2}$.

In the first and second years of settlement of the

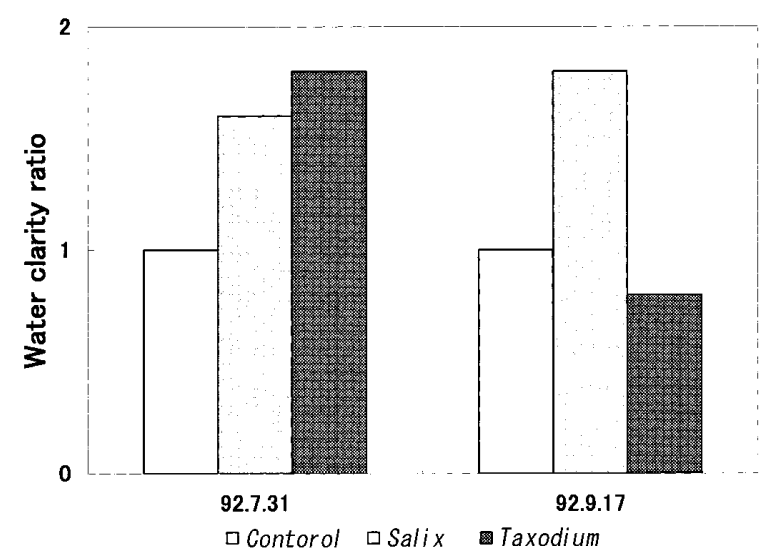

Fig. 2. Determination of clarity water floating planters, a nest of little grebes (Podiceps) was formed on a planter floating in the flood reservoir at FFPRI. In the experimental areas in Kasumigaura, nests of Acrocephalus arundinaceus, the little grebe and Streptopelia orientalis were observed because the planters and planted trees under water were arranged among existing reed fields and also because the plant communities were very close to the natural conditions ${ }^{2}$.

In the planters with a limited spacing for the development of roots, roots of $T$. distichum and I. pseudacorus coexisted with one another. The environment of the planters was assumed to be favorable for planted trees and aquatic organisms, because there were no symptoms of growth inhibition, and living chironomides and dragonfly nymphs were observed.

\section{Discussion}

Our objectives were to develop a continuous plant community in eutrophic lakes from the shoreline to the lake bed and to improve the aesthetics of lakes and irrigation ponds by establishing forests along the shoreline. Tree species suitable for this purpose, however, are quite limited due to the excess of water in the soil on the shore and by the wet sediments that contain undecomposed organic substances.

Based on the results of previous studies and vegetation surveys, 2 species of Salix (Salix gilgiana and $S$. triandra) and Taxodium distichum were selected as candidates for the planting of tree species along the shoreline ${ }^{1)}$. S. gilgiana is one of the dominant tree species of the vegetation community growing in riparian forests everywhere in Japan and $S$. triandra is a native woody plant growing in wetlands. In addition, $T$. distichum, which is native to Florida, North America, is wellknown in Japan as a tree species for the revegetation of shorelines in Japanese parks ${ }^{2}$.

To improve the water quality and aesthetics on the revetment banks made of concrete in the lakes and ponds, it is important to develop technologies for growing vegetation on the water surface from the shoreline to beyond it. In areas almost devoid of vegetation, the reestablishment of lakeside forests is possible by restoring continuous aquatic communities. Reestablishment of lakeside forests can provide habitat for fish and birds, if the restoration of forest sites along the shoreline can be achieved.

Trees on planters grew well and formed a larger number of rootlets and thick prop roots than the trees in the raft culture. In fact these thick prop roots were not produced in planted trees in the raft culture ${ }^{1)}$. Fine roots of $T$. distichum and S. gilgiana elongated and became entwined into the spacings of charcoal in the planters, 
indicating that the whole planter structure could promote the development of fine roots of the planted trees.

Natural floating islands with growing trees and grasses can be observed throughout Japan: such as Ukishima Swamp, Hokkaido; Ukishima Inari Shrine, Asahimachi, Yamagata Prefecture; and Isawa Ukishima in Shingu, Wakayama Prefecture ${ }^{4}$. These natural floating islands provide habitat for herbaceous swamp plants and many trees ${ }^{4)}$.

Weeding was necessary for the cuttings of $S$. trian$d r a$, because their growth was suppressed by the surrounding vegetation.

After observation of these phenomena, the artificial settlement of breeding areas of birds could be achieved by this planting method.

The above method for the settlement planters may enable to promote test plantings along the shorelines of lakes and ponds that are almost devoid of vegetation.

Water in the floating planter which was planted with S. gilgiana was 1.8 times clearer than the water in the control pond (Fig. 2). It appears that $S$. gilgiana could remove a large amount of suspended sediment from the water, because its roots grew denser and finer in water when planted on water.

The floating planter method was also found to provide breeding sites for the little grebe.

\section{References}

1) Nemezawa, T., Kubota, M. \& Yoshitake, T. (1998): N, P analysis of component case of Salix gilgiana. Jpn. Soc. Revegetation Technol. Assoc. Urban Tree-Plant. Subcomm. Summ., 7, 19-20 [In Japanese].

2) Yoshitake, T. (1994): Water purification function by trees. In Bio-Renaissance Program No.3. Agriculture, Forestry and Fisheries Research Council Secretariat, 46-58 [In Japanese].

3) Yoshitake, T. (1995): Refreshing eutrophic lakes by lakeside forests. APAST, 14, 14-17 [In Japanese].

4) Yoshitake, T. (2000): Restoring an Eutrophic Lake with Water-cultured Forests. Farming Jpn., 34, 38-42. 